\title{
O mito da liberdade de expressão em cinco notícias $^{1}$
}

\section{Five newsreports on the myth of freedom of expression}

Bárbara Heller²

1 Texto apresentado durante o XXXVIII Congresso Brasileiro de Ciências da Comunicação da Intercom (Sociedade Brasileira de Estudos Interdisciplinares da Comunicação), realizado no Rio de Janeiro de 4 a 7 de setembro de 2015. 


\section{Resumo}

A censura, na contemporaneidade, é uma das formas de violência simbólica que ainda afeta cidadãos dos mais variados países e regimes políticos do planeta. Este artigo contempla cinco notícias veiculadas pela internet sobre mulheres vítimas de censura em 2014 e questiona se o silenciamento que Ihes é imposto contribui para o apagamento de suas memórias. Para isso, recorremos a teóricos que relacionam História, Cultura e Comunicação como Beatriz Sarlo, Alain Touraine, Tzvetan Todorov, Venício Artur Lima, Walter Benjamin e Cristina Costa. A conclusão a que chegamos é que palavras, narrativas e memórias não desaparecem, apesar dos esforços - menos ou mais violentos - de silenciá-las.

\section{Palavras-chave}

Censura; mulheres; memória; narrativa. 
Censorship, in contemporary times, is a form of symbolic violence that still affects citizens of various countries and political systems around the world. This article includes five reports published in 2014, on the internet, about women who were censored. This article also questions whether avoiding them to speak contributes on erasing their memories. For this, we fell back on specialists who relate History, Culture and Communication as Beatriz Sarlo, Alain Touraine, Tzvetan Todorov, Venício Artur Lima, Walter Benjamin and Cristina Costa. We came to the conclusion that words, narratives and memories don't disappear, although the attempts - less or more violent - to silence them.

Keywords

Censorship, women, memory, narrative. 
O crítico Tzvetan Todorov afirma que

o estatuto da memória nas sociedades democráticas não parece definitivamente garantido. Talvez sob a influência de alguns escritores talentosos que viveram em países totalitários, a valorização da memória e a simultânea acusação contra o esquecimento difundiramse nestes últimos anos fora do seu contexto original (2002, p. 141).

As palavras deste historiador e filósofo búlgaro fazem todo o sentido no contexto brasileiro. No dia 24 de novembro de 2014 saiu publicada na Folha de S. Paulo a notícia de que o direito ao esquecimento seria debatido no Supremo Tribunal Federal. De um lado do processo estava a TV Globo, que rememorou o caso Aída Curi, estuprada e assassinada por jovens da classe média do Rio de Janeiro em 1958. De outro, estavam seus familiares, que pediam indenização, alegando que a emissora estava abrindo antigas feridas. Também há, genericamente falando, casos de acusados cujas penas já foram cumpridas e que por isso mesmo reivindicam o direito de serem esquecidos.

Não se trata apenas de debater, como sugerem estudiosos da memória como Henri Bergson ou Gilles Deleuze, que o passado não existe, uma vez que ele só se faz presente quando é acionado e ressignificado. Ou de questionar se assuntos da vida privada, quando de interesse público, podem e devem ser publicados, independentemente dos desejos de seus protagonistas. Trata-se, ao fim e ao cabo, do direito à liberdade de informação e de expressão, tema ainda tão polêmico, que muitas vezes cabe à justiça determinar quais notícias, informações, imagens etc., podem circular e em quais suportes midiáticos.

Além dos aspectos jurídicos, há também os emocionais, uma vez que tudo que se liga ao passado (longínquo ou recente) está pleno de sensações. São elas que impedem o apagamento do passado. Basta um aroma, uma música, um desenho, uma palavra, que ele nos toma de assalto, mesmo quando não é convocado. Incontrolável e soberano, o passado pode ser, no máximo, silenciado. Preservado pelas narrativas - especialmente pelas histórias de vida - o passado "é grande demais para ser entregue ao entusiasmo ou à cólera" (TODOROV, 2002, p. 141).

Segundo Beatriz Sarlo (2007), existem as narrações massivas, isto é, os grandes eventos, que são constituídos por um círculo hermenêutico fechado, normatizador das visões dos fatos e agente de um princípio organizador, com começo, meio e fim. Constrói-se, assim, uma falsa linha do tempo, na qual se elencam heróis e destituídos e se oferecem mais certezas que hipóteses. 
Um princípio organizador simples exerce sua soberania sobre acontecimentos que a história acadêmica considera influenciados por princípios múltiplos. Essa redução dos campos das hipóteses sustenta o interesse público e produz uma nitidez argumentativa e narrativa que falta à história acadêmica (SARLO, 2007, p. 14).

As matérias de que trataremos no artigo não são "massivas", mas da vida cotidiana, da história cultural de cinco países diferentes. Elas nos permitem refletir sobre os danos provocados pelo cerceamento à liberdade de expressão no tempo presente e, ao mesmo tempo, projetam para o futuro como os fatos, mesmo os não narrados, podem ser reativados pela memória. Na Inglaterra, uma mãe recusa-se a se sentir ofendida porque amamentava seu filho publicamente em um hotel em Londres (The Guardian, 02/12/2104); no Irã, uma mulher é condenada à prisão por tentar assistir a um jogo de vôlei (Notícias.terra.com.br, 02/11/2014); no Brasil, um espetáculo teatral é censurado em Minas Gerais, por mostrar um beijo na boca entre duas mulheres (Mais Notícias, 16/07/2014); no Canadá, uma fotógrafa tem sua conta no Instagram censurada porque clicou seus pelos pubianos ligeiramente acima da calcinha do biquíni (Huffington Post, 17/10/2014) e, finalmente, na Turquia, a afirmação do seu presidente, Recep Tayyip Erdogan, de que não existe igualdade entre gêneros (Avanzada.reduc.edu.cu, 27/11/14).

Trata-se, portanto, de uma pequena amostragem, mas bastante significativa, da prática censória sobre mulheres na contemporaneidade, nas mais diversas partes do planeta e regimes políticos. Não é por acaso que todas elas giram em torno de protagonistas femininas. As mulheres são consideradas, segundo Beatriz Sarlo, especialistas na dimensão do público do privado e, por isso, ocupam importante lugar na história cultural. (2007, p. 17). Alain Touraine, na recente obra O mundo das mulheres, reforça esse pensamento quando afirma que

o movimento feminista transformou profundamente a condição das mulheres em diversos países (...) Entre os cidadãos dos países ocidentais, somente um pequeno número rejeita as conquistas e as ideias do feminismo.[...] As ações contra a desigualdade e as discriminações representam efetivamente a parte mais visível da ação feminina, e as consequências no comportamento das mulheres são as mais profundas e também as que têm maior visibilidade (2010, p. 19).

Também são elas as grandes contadoras de histórias, como a inesquecível Sherazade, cuja habilidade de criar ganchos narrativos inesperados ao sultão Ihe permitiu escapar da morte certa e calculada. No entanto, as mulheres que serão 
tratadas adiante são "comuns", que não se aproximam em nada das personagens de histórias que compõem o imaginário da humanidade ou das celebridades que as mídias procuram noticiar. Elas apenas buscam a "construção de si", expressão que tomamos emprestada de Alain Touraine, ou seja, que desejam ser sujeitos de suas próprias existências. Trata-se de mulheres responsáveis pela sua individualidade, pela liberdade de escolher sua própria vida, "[em] oposição a toda definição imposta de fora" (TOURAINE, 2010, p. 47). São, portanto, mulheres narradoras dos eventos que protagonizam, que não aceitam ser narradas e, muito menos, silenciadas.

Recorremos agora a Walter Benjamin, especificamente ao seu texto $O$ narrador, em que expõe a diferença entre narrador e romancista. O primeiro conta aquilo que experimentou e se integra aos ouvintes; o segundo é um indivíduo isolado, que não recebe nem sabe dar conselhos. O narrador não quer contar as coisas como um relatório ou uma informação, ao contrário, quer se misturar naquilo que relata: "Assim se imprime na narrativa a marca do narrador, como a mão do oleiro na argila do vaso" (BENJAMIN, 1994, p. 205).

A censura é uma tentativa, na maior parte das vezes política, de silenciamento dos discursos do narrador ou do romancista, orquestrada por regimes políticos autoritários, mas também pelos democráticos. Nesse último, seria de se esperar que indivíduos ou grupos sociais tivessem o direito de saber por si mesmos, conhecer e narrar suas próprias histórias, mas não é o que acontece, como mostram as notícias a seguir. Há sempre mediações, interdições e conflitos de interesse que fazem prevalecer direitos de setores hegemônicos da sociedade em detrimento dos demais, entre eles, das mulheres, apesar das inquestionáveis conquistas dos movimentos feministas desde o século XIX no mundo ocidental.

\section{Notícia 1 - "O incidente no [Hotel] Claridgde é absurdo - Eu me recuso a ser ofendida"3}

$\mathrm{Na}$ Inglaterra, Louise Burns amamentava seu filho no hotel Claridge, quando um garçom pediu-Ihe para cobrir o rosto do bebê com um guardanapo. Ao tuitar o ocorrido, muitas pessoas, ao invés de apoiarem Louise, ofenderamse com ela por ter amamentado seu bebê publicamente. O que chama a atenção nesse episódio são pelo menos quatro características: 1. A maneira passional de a articulista, Deborah Orr, comentar o episódio; 2. A vigilância simulada ao corpo da mulher, quando o garçom pede para cobrir o rosto do bebê e não seu seio; 3 . A imediata midiatização do fato; 4 . A reação conservadora nas redes sociais num país democrático, cuja capital ficou conhecida pela sua contracultura nos anos 1970 e multiculturalidade na contemporaneidade. 


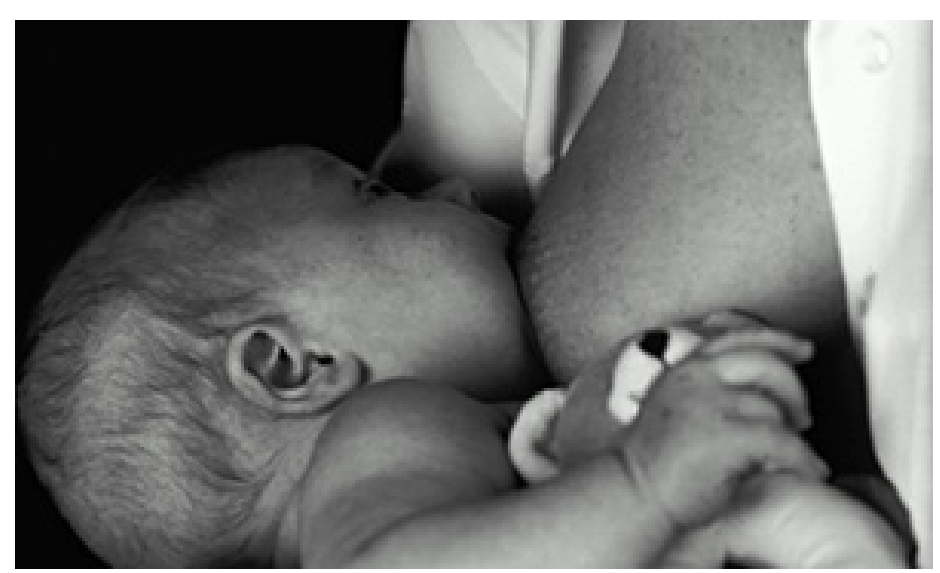

Figura 1: Quem pensa que não deve ser exposto a uma cena de amamentação precisa se perguntar por que faz tamanha confusão em sua cabeça (tradução nossa).

Foto: Getty Images ${ }^{4}$.

Deborah Orr, a articulista, assim como Louise, a mãe, se utilizaram das novas mídias para relatar o episódio. Ocorre, no entanto, que apesar de a primeira não ter estado presente à cena, tudo que se lê é apenas sua opinião pessoal, como já se oberva no primeiro parágrafo: "Sinto pena é do garçom. E do supervisor dele. E de qualquer um que ao invés de ficar tocado por um momento maravilhoso da vida, de ver um lindo bebê se alimentar naturalmente, se sente ofendido (tradução nossa)"5.

A voz de Louise é silenciada no texto; não há nenhum recurso como o uso das aspas ou paráfrases para indicá-la. A narração, portanto, embora em primeira pessoa, acaba sendo indireta. Deborah Orr, concluímos, não se comportou como uma narradora, no sentido benjaminiano. Não pôde se misturar aos fatos, porque não os vivenciou e, apesar de condenar a censura ao corpo, calou a voz de quem mais precisava ser ouvida e protegida: a da mãe. O máximo que a articulista alcançou foi ser porta-voz de uma parte da população britânica que combate o falso moralismo e ajudar na campanha pela amamentação em ambientes públicos. E, ao final, proclama:

Bebês nada sabem sobre o hotel Claridge, nem sobre garçons, nem sobre o Twitter, nem sobre ofensa, é assim que todos nós começamos. A habilidade de se sentir ofendido pela mera visão de amamentação

\footnotetext{
4 Do original: "Every person who thinks that they should not be exposed to breastfeeding needs to ask themselves how they got so messed up in the head". Disponível em: http://www.theguardian.com/commentisfree/2014/dec/02/claridges-breastfeedingbabies. Acesso em: 10 jul. 2015.

5 Do original: "It's the waiter I feel sorry for. And the waiter's supervisor. It's anyone who sees a tiny baby doing what comes naturally and, instead of being touched for a moment by the wonder of life, gets "offended".
} 
é algo ensinado e aprendido. Não é algo apenas contra a mulher; é contra o humano (tradução nossa) ${ }^{6}$.

Publicada em 2 de dezembro de 2014, essa notícia não nos parece sequer original. Tivemos, no Brasil, a mesma situação: em março de 2011 uma funcionária do Itaú Cultural, em São Paulo, impediu uma visitante de amamentar seu filho publicamente. A reação, organizada pelas redes sociais, permitiu que, poucos dias depois, um grupo de mais de 50 mulheres dessem de mamar ao mesmo tempo a seus bebês, no saguão do referido Instituto.

\section{Notícia 2 - "Iraniana é condenada a prisão por tentar ver jogo de vôlei"}

Esta curta notícia conta que Ghoncheh Ghavami, com dupla cidadania (iraniana e britânica), foi detida em junho de 2014 em um ginásio de Teerã, enquanto esperava o início da partida da Liga Mundial masculina entre Irã e Itália.

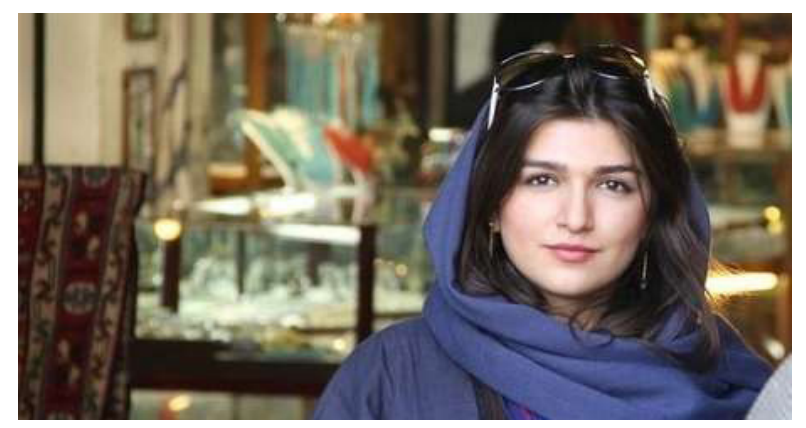

Figura 2: Ghoncheh Ghavami. Foto: Reprodução / Change.org7.

A jovem, liberada depois de algumas horas, voltou a ser detida, "por motivos de segurança", acusada de ter feito propaganda contra o regime. Ao todo, permaneceu 126 dias presa e seu julgamento ocorreu em outubro de 2014. Ainda segundo a reportagem, todas as mulheres no Irã, incluindo jornalistas credenciadas, são proibidas de assistirem a jogos de futebol e de vôlei masculinos para serem poupadas dos comportamentos "obscenos" da torcida masculina.

Trata-se de um regime republicano e teocrático, que censura as mídias sociais e condena seus inimigos à morte, apesar dos protestos mundiais e da própria ONU. Ghoncheh Ghavami, por ter dupla cidadania, assemelha-se ao perfil do grupo das muçulmanas estudadas pelo sociólogo Alain Touraine, na França, em 2004.

6 No original: "Babies know nothing of Claridge's, of waiters, of Twitter, of offence; and that is how we all started out. Babies know breasts only as givers of milk. The ability to take offence at the sight of breastfeeding is a thing that is taught and learned".

7 Disponível em: http://noticias.terra.com.br/mundo/oriente-medio/iraniana-e-condenada-a-prisao-por-tentar-ver-jogo-de-volei ,2533141892f69410VgnCLD200000b2bf46d0RCRD.html Acesso: 12 jul. 2015. 
Elas empenham-se tanto pela emancipação dessas opressões, que mal percebem outros objetivos que não este (2010, p. 137). Apesar de conscientes dos perigos a que estão sujeitas, não desejam renunciar à sua identidade muçulmana, menos ainda à sua laicidade (2010, p. 145). Touraine é enfático em sua conclusão:

Será que ainda podemos imaginar que essas mulheres muçulmanas, de um lado, devem escolher entre uma crença e uma comunidade e, de outro, a sociedade francesa e laicidade? Ao contrário! O que as define é a ação permanente, em geral dolorosa, para não ter que escolher, para não se privar nem de uma parte da própria personalidade nem da outra, para ser diversas pessoas em uma (2010, p. 146).

Trata-se, na verdade, de não ter de escolher entre uma cultura ocidental e oriental. Ghoncheh Ghavamivi é mais do que si mesma; é um símbolo, pois representa uma personalidade múltipla, multicultural, que tenta se libertar do antifeminismo e se comunicar por si mesma, mesmo quando está em solo iraniano.

A notícia, não assinada, traz o logotipo da AFP, isto é, da Agence France Presse, tida e havida como uma das mais prestigiadas do mundo. Fundada em 1835, é conhecida por cobrir todos os tipos de fatos ao redor do mundo: de esportes a política, das últimas descobertas científicas a comportamentos. Portanto, cumpriu o papel que cabe às mídias: narrou, mas, principalmente, informou. Ou seja: retirou do leitor sua livre interpretação para que o episódio narrado ficasse circunscrito a uma determinada amplitude. O narrador, como lamentaria Walter Benjamin, não "imprimiu sua mão como a mão do oleiro na argila do vaso"; ao contrário: enquanto difusor de uma mera informação, tornou-a compreensível, verificável, precisa, sem surpresa, como sugeriu no trecho que segue:

Cada manhã, recebemos notícias de todo o mundo. E, no entanto, somos pobres em histórias surpreendentes. A razão é que os fatos já nos chegam acompanhados de explicações. Em outras palavras: quase nada do que acontece está a serviço da narrativa, e quase tudo está a serviço da informação (BENJAMIN, 1994, p. 203).

\section{Notícia 3 - "Sesiminas censura espetáculo com beijo entre mulheres"}

Para quem já estudou a censura no teatro no Brasil, a notícia não é surpreendente, nem nova. Mesmo em tempos inquestionavelmente democráticos, ainda se vetam espetáculos tidos como atentados à moral, por haver mulheres trocando beijos na boca, em pleno palco. Esta decisão os iguala às cenas de nudez, 
de erotismo ou de pornografia da filmografia nacional de um passado não muito distante, em que censores contratados pelo Estado exigiam supressão de tais sequências ou, o que era ainda pior e mais cômico, que se cobrissem os seios e os genitais masculinos e femininos com bolinhas ou outros artifícios nada eficientes.

A peça Beijo na Boca, de Ronaldo Boschi, diretor de teatro e fundador do CPT (Centro de Pesquisas Teatrais) versa sobre uma relação amorosa entre duas mulheres que, ao final, se beijam. Ela deveria estrear para comemorar o $40^{\circ}$ aniversário do grupo, mas isso acabou não acontecendo, apesar de a diretora, filha do autor, acatar os cortes propostos pelo juizado de menores e alterar várias cenas.

É o que conta Gustavo Rocha, em cujo primeiro parágrafo já deixa claro aos leitores seu engajamento contrário à censura, ao reproduzir os versos de Maria Bethânia, cantados nos idos anos de 1965: "É um tempo de guerra, é um tempo sem sol". Logo em seguida, o articulista faz uma pergunta puramente retórica, para realçar sua resposta enfática: "Se a música [de Maria Bethânia] parecia propícia pelo contexto histórico (ditadura militar desde 1964), ela poderia soar nostálgica a quem a ouve em tempos de democracia consolidada no Brasil, certo? Errado".

Gustavo Rocha é um "narrador-moleiro", conceito que adaptamos das ideias de Benjamim: entrevistou e deu voz à diretora Roberta Luchini Boschi, além de defender suas causas e também informar os leitores. Sua narrativa parece estar mergulhada na vida do narrador, como no trecho que segue: "Um pai de uma aluna, menor de idade, me disse que a filha estava incomodada com seu papel. A menina aparecia de roupa íntima por cima de um collant. Ela não ficava nua. Não tem pornografia na peça"8.

Embora a aluna em questão não fosse interpretar o beijo, várias cenas foram alteradas pela diretora e informadas ao Sesi. Ainda assim, o pai da atriz mirim ameaçou chamar o Juizado de Menores, caso a peça fosse encenada. $O$ Sesi, por decisão jurídica, achou por bem cancelar o espetáculo. Não se trata, portanto, de atentado a menores de idade, mesmo na condição de atores, uma vez que, por força de lei no Brasil, quando atuam em espetáculos, têm contratos assinados por seus pais ou responsáveis. Trata-se, isso sim, de uma atitude intimidatória do pai da menina.

Já é consenso entre os que estudam o Brasil que a cultura portuguesa imposta desde o momento em que fomos oficialmente descobertos não só tentou eliminar qualquer vestígio das crenças, línguas e costumes dos indígenas, nossos primeiros habitantes, como também introduziu a prática da censura. Segundo Cristina Costa,

8 Disponível em: http://www.otempo.com.br/divers\%C3\%A3o/magazine/sesiminas-censura-espet\%C3\%A1culo-com-beijoentre-mulheres-1.883877 Acesso: 12 jul. 2015. 
foi fácil adaptar para a regulamentação do campo artístico práticas arbitrárias com as quais se costumava defender a religião e os interesses lusitanos. A passagem, portanto, de rotinas de controle, fiscalização e demonstrações de poder do Período Colonial para o Império se deu sem resistência [...] (COSTA, 2008, p. 52).

Até hoje, em plena vigência do regime democrático, o público ainda é visto como frágil, necessitando da tutela de um governo que se proclama detentor de critérios que garantam os bons usos e costumes. A ironia dessa proibição, segundo a notícia, é que o próprio autor da peça foi atuante, nos tempos da ditadura militar, convivendo e combatendo a censura. Impossível não lembrar das páginas finais do livro Censura em cena, nas quais sua autora, Cristina Costa, elenca cinco grandes prejuízos que a censura trouxe para a cultura brasileira:

1. A censura faz aumentar o respeito e a consideração pelo artista estrangeiro e enfraquece a produção nacional; 2. A censura homogeneíza e pasteuriza a produção artística, pois o corte de palavras ou troca de expressões enfraquecem conflitos e abrandam paixões; 3. A censura prejudica os menores, os amadores, os alternativos: o poder torna sempre mais frágil o artista iniciante que acaba desistindo de resistir sozinho; 4. A censura acovarda o artista: os castigos que a censura infringe ao artista causam males indeléveis a seu caráter e à sua personalidade; 5 . A censura, como toda forma de coerção, não encontra limites (2008, p. 262-267).

O CPT, que segundo a reportagem produz espetáculos amadores em profusão, sofreu sérios prejuízos com a intransigência da censura, mas quem mais perdeu, certamente, foram o público e a liberdade de expressão, num país que já cantou tanto como forma de protesto, como de nostalgia, os versos, desta vez de Caetano Veloso: "é proibido proibir".

\section{Notícia 4 - "Por que o Instragram censurou meu corpo"9}

Assim como acontece no Facebook e Twitter, a rede social Instagram também sofre censura quando são expostos corpos femininos. Quando a conta da fotógrafa canadense Petra Collins foi retirada do ar, a sensação que teve foi a de ter sofrido uma violência física:

Quando minha conta foi deletada me senti como se estivesse com dores físicas, como se o público viesse em minha direção com uma 
navalha de barbear, enfiando um dedo na minha garganta, forçandome a vomitar, forçando-me a me submeter a uma imagem de beleza imposta pela sociedade (tradução nossa).

Essa notícia, narrada em primeira pessoa, revela a história da fotógrafa que postou uma foto em que aparecem seus pelos pubianos sobre uma calcinha de biquíni.

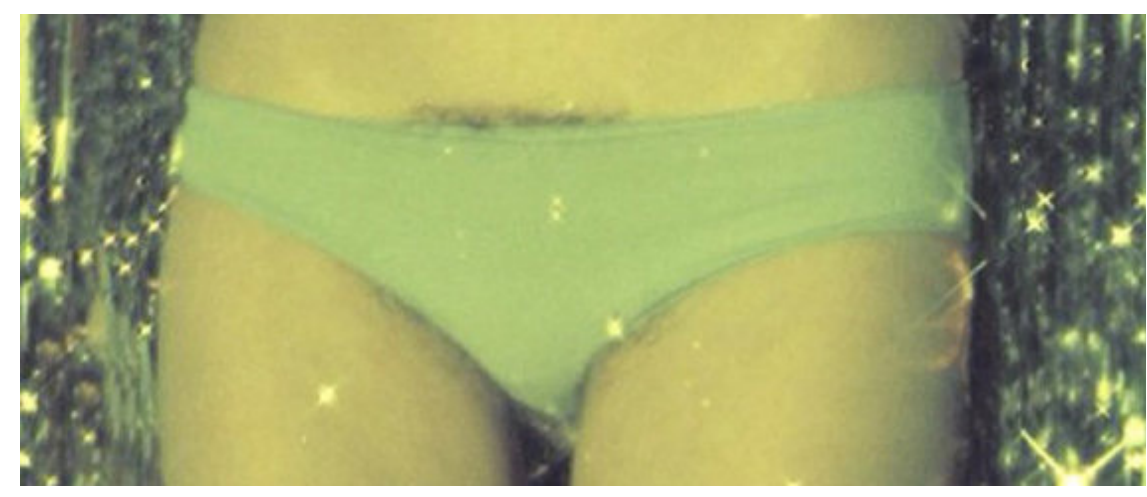

Figura 3: Calcinha e pelos pubianos de Petra Collins censurada no Instagram. Foto de Petra Collins ${ }^{10}$.

Militante do corpo livre, não assujeitado às normas da estética midiática, a fotógrafa se diz acostumada a ver notícias que difamam mulheres por serem gordas ou vítimas de estupro, que mostram seus pelos ou sua menstruação, ainda que por desenhos em camisetas. Mais ainda: que se diz feliz por conseguir usar a internet e a tecnologia para militar a favor de um tratamento mais amigável entre as próprias mulheres. Reconhece, também, que os perfis das redes sociais ajudam seus usuários a ter audiência, a começar uma discussão e promover mudanças.

Reconhece-se, portanto, na censura sofrida por essa usuária, o poder político de um grupo social que, embora não se saiba quem são seus componentes, sabese como agem. Ele é tão poderoso que condiciona as ações e crenças dos demais e também a transmissão de formas simbólicas. Na contemporaneidade, esse poder passa, necessariamente, pela mídia, mas não é compartilhado de forma igualitária entre seus usuários. Como diz Venício Lima,

o direito à comunicação constitui-se em direito civil - liberdade de expressão - em direito político - direito à informação - e em direito social - através do direito a uma política garantidora do acesso do cidadão aos diferentes meios de comunicação (2011, p. 220).

10 Disponível em: http://www.huffingtonpost.com/petra-collins/why-instagram-censored-my-body_b_4118416.html Acesso em: 12 jul. 2015. 
Certamente Petra Collins sente-se destituída de seu direito social, mas também faz forte apelo emocional quando insere, ao final da página, uma imagem em que está em lágrimas e se pergunta o que irá acontecer se deixarmos que a censura interceda em nossa vida real como em nossos perfis. Fazendo-se de vítima e de injustiçada, seu relato é baseado exclusivamente em sua experiência pessoal, o que a acaba isolando de seus leitores. Seu protesto apoia-se constantemente no pronome possessivo "my" ("meu"), como na frase adiante, em que aparece em maiúsculas:

Nada fiz que violasse os termos de uso. Não há nudez, violência, pornografia, coisas fora da lei, incitação ao ódio, ou imagens infratoras. O que eu realmente fiz foi uma imagem do MEU corpo que não vai ao encontro do padrão social de "feminilidade" (tradução nossa) ${ }^{11}$.

Torna-se, neste aspecto, uma narradora de romances, no conceito de Walter Benjamin, distanciada. E, isso, em certa medida, esvazia sua militância, uma vez que não consegue angariar, por argumentos que não sejam exclusivamente passionais, a adesão de outros militantes contra a censura nos novos suportes midiáticos.

\section{Notícia 5 - "Presidente turco niega por completo la igualdad entre hombre y mujer"}

A Turquia tem sido mais reconhecida pelos seus aspectos turísticos do que pelos políticos. Afinal, seu presidente, em nome da religião, tentou impor às mulheres a tarefa de terem ao menos três filhos, condenar o aborto e o adultério. Não se trata aqui de julgar a religião islâmica, mas de reconhecer que, em termos de emancipação feminina, a Turquia tem retroagido. As mulheres no Ocidente conquistaram, ao longo dos séculos XIX e XX, uma relativa independência financeira, emocional e do corpo, após muitas lutas. Atualmente muitas delas ocupam as mais altas posições nas vidas corporativa e política, como no Brasil, na Alemanha, na Argentina, etc.

Vítimas da violência simbólica, as turcas também o são da violência física. Segundo cifras oficiais, cerca de 214 mulheres foram assassinadas por seus próprios companheiros, apenas no ano de 2013. Também são frequentes os ataques que sofrem por seus companheiros que jogam ácido em seus rostos, deformando-os e mutilando-os. Além de não terem direito à voz, não têm oportunidade de trabalho remunerado e são julgadas, quando cometem infrações, com leis diferentes das dos homens.

11 Do original: "I did nothing that violated the terms of use. No nudity, violence, pornography, unlawful, hateful or infringing imagery. What I did have was an image of MY body that didn't meet society's standard of 'femininity'". Disponível em: http://www. huffingtonpost.com/petra-collins/why-instagram-censored-my-body_b_4118416.html. Acesso: 14 jul. 2015. 
Todos esses aspectos foram reforçados pelo discurso de Recep Tayyip Erdogan, presidente da Turquia, em 24 de novembro de 2014, em Ankara, numa conferência sobre mulheres e justiça. Segundo ele, não é correto colocar ambos os sexos em posições iguais "porque tanto em sua essência, como em suas condições, são diferentes" (tradução nossa) ${ }^{12}$. Para ele, a prioridade das mulheres deveria ser a maternidade, a mais alta posição a que podem almejar. E, para coroar sua posição, critica as feministas, por serem incapazes de compreender e aceitá-la.

Retomamos mais uma vez Alain Touraine, para quem as mulheres muçulmanas, quando vivem no mundo ocidental e têm a possibilidade de se expressar, refletem com clareza sobre sua experiência pessoal e sobre a das outras mulheres. Reprimidas sexualmente e privadas dos direitos individuais, mas conscientes dos ritos, das proibições nas quais são aprisionadas, das desigualdades entre meninas e meninos, ainda assim permanecem fortemente ligadas ao Islã.

O sociólogo conclui que mesmo em cenários onde as mulheres são "arrasadas pelas proibições e injustiças, elas sempre fazem para transformar-se em agentes da própria libertação'" (TOURAINE, 2010, p. 151). A reportagem que permitiu essas reflexões foi escrita em terceira pessoa, sem autoria definida, e não tem o logo de nenhuma agência internacional de notícias. No entanto, estas ausências não desabonam a "verdade" da informação uma vez que a violência física e simbólica contra as muçulmanas é difundida em todas as mídias e testemunhada por suas vítimas.

O que chama a atenção nesta reportagem e que justifica sua inclusão no artigo é a prática milenar de um poder autoritário que exclui as mulheres de todas as instâncias públicas e as condena ao silenciamento, ao ocultamento de seus corpos, à repressão de sua sexualidade. Suas histórias e memórias só serão lembradas em situações muito específicas: se estiverem vivendo no Ocidente, se os regimes teocráticos forem substituídos por democráticos e, principalmente, se a cultura daqueles países deixar de ser essencialista, isto é, se abandonar o discurso sobre a natureza das mulheres e sobre a diferença entre a psicologia masculina e a feminina (TOURAINE, 2010, p. 47).

\section{Considerações finais}

Como expressa Todorov, "a memória não é nem boa nem má" (2002, p. 191). Podemos sacralizar ou demonizar os depoentes, reconhecermo-nos nos personagens "positivos" ou nos horrorizarmos com os "maus". Ainda seguindo seu

12 No original: "porque, tanto en su esencia como en sus condiciones, son diferentes". Disponível em: http://avanzada. reduc.edu.cu/sitioanterior/index.php/mundo2/9251-presidente-turco-niega-por-completo-la-igualdad-entre-hombre-y-mujer. Acesso em: 14 jul. 2015. 
raciocínio, nada garante também que ao ouvirmos o relato de um crime "abracemos a causa das vítimas" (20002, p. 196); é possível que um sádico ou um voyeur se identifique com o criminoso. Também é possível que uma vítima de uma violência passada se torne um agressor no tempo presente ou, dito de outra maneira: "Uma vez introduzido na História, o mal não desaparece com a eliminação de seu agente original" (TODOROV, 2007, p. 198).

Os exemplos aqui analisados, ainda que brevemente, mostram diversos males cometidos contra mulheres em diferentes países e regimes políticos. Todas foram vítimas de violência física, simbólica ou de ambas e de uma ação censória. O risco de suas histórias caírem no total esquecimento potencializa à medida que seus relatos não fazem parte dos "grandes eventos" e seus interlocutores nem sempre se identificam com eles. Beatriz Sarlo esclarece que "propor-se não lembrar é como se propor não perceber um cheiro, porque a lembrança, assim como o cheiro, acomete, até mesmo quando não é convocada" (2007, p. 10) e que "só se narra ou se remete ao passado por um tipo de relato, de personagens, de relações entre suas ações voluntárias e involuntárias [...]" (2007, p. 12).

Isso quer dizer que para preservar a memória das mulheres, dos homens, das vítimas ou dos opressores é necessário, em primeiro lugar, garantir que cada pessoa possa exercer seu direito à comunicação, isto é, garantir uma "relação constitutiva entre a comunicação, o poder e a cidadania" (LIMA, 2011, p. 215). Mas, ainda que não exista essa condição ideal, o poder da palavra permanece e, por meio dela, brotam-se as narrativas e preservam-se as memórias.

Eliminando-se a censura, portanto, permite-se imediatamente a disseminação das narrativas, inspirada pela deusa grega da memória, Mnemosyne. É por meio dela que se funda a cadeia da tradição, que se transmitem os acontecimentos de geração em geração, que se permite esquecer para também poder se lembrar e se lembrar para também poder se esquecer. 


\section{Referências}

BENJAMIN, W. "O narrador: considerações sobre a obra de Nikolai Leskov". In: Magia e técnica, arte e política: ensaios sobre literatura e história da cultura. São Paulo: Brasiliense, 1994, p. 197-221.

COSTA, C. Censura em cena: teatro e censura no Brasil. São Paulo: Edusp, Fapesp, Imprensa Oficial, 2008.

LIMA, V. A. Regulação das comunicações. São Paulo: Paulus, 2011.

SARLO, B. Tempo passado: cultura da memória e guinada subjetiva. São Paulo: Companhia das Letras; Belo Horizonte: Editora Ufmg, 2007.

TODOROV, T. Memória do mal, tentação do bem. São Paulo, Arx, 2002.

TOURAINE. A. O mundo das mulheres. Petrópolis: Vozes, 2010.

submetido em: 20 ago. 2015 | aprovado em: 22 nov. 2015 